\title{
(2) \\ Vegetation Analysis of Urban Ethnic Markets Shows Supermarket Generalists and Chinatown Ethnic-specialist Vendors
}

\section{Research}

\section{Abstract}

The growing cultural diversity in the United States calls attention to ethnobotanical studies of urban ethnic food markets. These venues illustrate dynamic interactions between people and plants. A market survey of the Chinatown markets in Honolulu, Hawai'i was conducted to collect empirical data on this culturally rich urban area. The objectives included: (1) To analyze the food plant richness of selected Chinatown markets in comparison to local mainstream supermarkets; and (2) To test the use of vegetation analysis to describe the structure of these markets (e.g., "ethnic markets"). Surveys and mapping of food plants at three market areas in Chinatown and three mainstream supermarkets were conducted between February and March 2006. Microsoft Excel and the Community Analysis Package programs were used to analyze and compare plant richness and the structure of vendors and markets. In all of the markets combined, 291 "fresh" food plant varieties were recorded, representing 42 plant families and a group of fungi. The mainstream supermarkets were more rich in varieties of food plants than the Chinatown market area (mean \pm s, $144 \pm 21$ vs. $95 \pm 23, p=0.05$, Mann-Whitney $U$ test). Allium cepa L. and Allium sativum L. were ubiquitous. The Mainstream market group contained significantly more sweet-fruits than the Chinatown market areas. Agglomerate cluster analyses revealed groupings of mainstream supermarkets, Chinatown market areas; further analysis of the Chinatown areas defined culturally identified "Filipino," "Vietnamese," and specialty fruits vendors. Mainstream supermarkets may be viewed as "generalists" while the Chinatown market areas and vendors may be viewed as "specialists" for an ethnic or cultural group or food plant commodity.

\section{Introduction}

In 2005, 35 million immigrants lived in the United States. That equates to $12 \%$ of U.S. population, and the high- est number of foreign-born residents in eight decades (Camarota 2005). This culturally rich population will undoubtedly have a big impact on food choices in the U.S. due to the strong link between food and ethnicity (Kalcik 1984). Food markets are an important venue to study the dynamic use of plants by ethnic and immigrant communities (Nguyen 2005b, Pemberton \& Lee 1996, Porterfield Jr. 1951, Wang \& Lo 2007, Whitaker \& Cutler 1966). The market acts to bring people of similar culinary traditions together as they provide the ingredients necessary for cuisine, which contributes to one's sense of ethnicity (Cunningham 2001, You-Kai et al. 2004). They are also an area where people of similar cultural backgrounds can meet, exchange information and reinforce community ties (Carter 1988). Because the growing immigrant population will continue to have an effect on food plant diversity in the U.S., ethnobotanical studies for empirical data and analysis of ethnic markets and on food plant use are important to understand and address the needs of an increasingly diverse U.S. population.

At $17.2 \%$, Hawai i ranks fifth for states with the highest percentage of immigrants in the total population (Cama-

\section{Correspondence}

My Lien Thi Nguyen, Environmental Studies Program, Biology Department, Box 731, Vassar College, 124 Raymond Avenue, Poughkeepsie, NY 12604. U.S.A.

mylien.t.nguyen@gmail.com

Katherine T. Doherty, Department of Botany, University of Hawai' i, Honolulu, Hawai i 96822. U.S.A.

Julia Wieting, Department of Anthropology, University of Hawai'i, Honolulu, Hawai i, 96822. U.S.A.

Ethnobotany Research \& Applications 6:063-085 (2008) 
rota 2005). Although Hawai i is an area of high cultural and ethnic diversity, ethnobotanical information regarding its food markets is antiquated (Chung \& Ripperton 1929); limited in breadth by focusing on a particular ethnic group (Nguyen 2006, Wester \& Chuensanguansat 1994), plant form or taxa (Nguyen 2005a, Staples \& Kristiansen 1999); or otherwise written for popular audiences (Bonk 1993, Kendrick 1999).

The Chinatown market and its surrounding historic district, in downtown Honolulu, has long been a gateway to Hawai i for many immigrants from Asia. The first arrival of Chinese to Hawai $i$ was in 1789 , but it was the arrival in 1852 of contract laborers needed for the growing sugar industry that led to the development of Chinatown. These early Chinese immigrants built stores to support the social and consumer needs of their Chinese community. Today Chinatown is known for its colorful and eclectic blend of many cultures, including Chinese, Filipino, Hawaiian, Japanese, Korean, Thai, and Vietnamese (Carter 1988). Cultural groups have described it as an important place for familiar traditional foods and contributing to their happiness with living in Honolulu (Nguyen 2003, Wester \& Chuensanguansat 1994).

Yet, in an urban environment, people may have the option of going to a mainstream supermarket to buy their foods. We pose the question: To what extent do these mainstream supermarkets provide the same food plants available in the ethnic markets? Few market surveys have considered this non-ethnic counterpart to the ethnic markets (Pemberton \& Lee 1996). To begin to understand the function of ethnic markets in relation to the mainstream supermarkets within an ethnically diverse community, we carried out a market survey and comparison of the food plant richness found in the Chinatown markets and mainstream supermarkets in Honolulu, Hawai i.

Market studies typically include descriptive statistics to describe the richness and diversity of plant resources available (earlier cited market studies). Vegetation analysis applied in ecological studies is used to describe, map and analyze communities of plants to determine the factors that control their presence and distribution (Causton 1988). Williams et al. (2000) used an ecological approach to analyze species richness and diversity of a medicinal market in Africa and conclude that the regional ethnic diversity probably contributes to the diversity of medicinal plants available at the market. Salick et al. (2006) also employed a presence/absence analysis of plants in their study of Tibetan medicine plurality. While these studies focused on medicinal plants, we have found no market studies using an ecological approach to describe the similarities or associations of food markets with regard to their plant taxa and ethnic or cultural identity of the market or individual market stall (or vendor).
Our objective in this study is to apply vegetation analysis to a food market survey. Often people describe individual vendors by an ethnic identifier, such as the "Chinese-," "Filipino-," or "Vietnamese-shop" (Yim 1998). We are interested in using a vegetation analysis to search for evidence that individual vendors in Chinatown represent ethnic or cultural shops that are identifiable by: (1) cultural indicator species (Garibaldi \& Turner 2004), food plants present in culturally specific cuisines (Nguyen 2007, Tan 2003); or (2) cultural plant assemblages, which are assemblages of food plants characteristic or culturally recognized for certain cuisines or food (Nguyen 2006, Rozin 1973). An example of a cultural plant assemblage would be a Vietnamese vendor typically sells a specific assemblage of aromatic herbs used for a Vietnamese noodle soup.

\section{Methods}

Our methods included a triangulation of market surveys and collections, descriptive statistics, and vegetation analysis:

ungi

(1) Between February and March 2006, the presence of fresh food plants at three market areas in Chinatown and three mainstream supermarkets were surveyed. An informed consent statement was prepared and given to the manager or representative seller of the market of the individual vendors. Markets are reported anonymously. In addition to presence, we designated and recorded general food plant forms. These are artificial plant form designations and do not necessarily equate to the botanical definition of the plant part utilized. These designations allowed us to compare markets according to their type of food plant offering and helped to facilitate the recording of plants in the markets. Plant forms included:

- fruit-sweet, for botanical fruits that are eaten for their sugar-sweetness;

- $\quad$ fruit-veg, for botanical fruits that are not sugar-sweet, and often designated as "vegetable;"

- leafy-veg, leaves or different sections of plant sections that are generally eaten as a "vegetable;"

- $\quad$ root, any food plant part that grows beneath the soil surface (e.g., true roots, corm, bulb, rhizome, tuber);

- $\quad$ aromatic (leafy or herbaceous plant with volatile oils and generally used as an herb),

- $\quad$ flower, flower buds and blossoms sold as food, and

- fungi. While fungi are not classified as plants, we included them in our survey because they were present in the markets with the fresh food plants.

These designations of food plant forms may not satisfy all reviewers, but these divisions are a starting point for the analysis we make here. In addition to the objectives described above, this study was partly conducted as research experience for students in an undergraduate ethnobotany course. This necessitated that the surveys be 


\section{Nguyen et al. - Vegetation Analysis of Urban Ethnic Markets Shows Supermarket Generalists and Chinatown Ethnic-specialist Vendors}

completed in one school semester. Thus, this survey is a snapshot of fresh food plant availability of the markets.

The three mainstream supermarkets were chosen due to their proximity to Chinatown. These markets included two national chains and one Hawai i state-wide chain. The three market chains are the largest suppliers of food to Honolulu. These mainstream markets provide meats, fish, dried goods, and other household items, in addition to fresh food plants. To have comparable surveys, the three Chinatown market areas included individual vendors that serve as the meat, fish, dried goods, and fresh food plant suppliers within delimited areas of Chinatown. These Chinatown market areas included 2 to 5 fresh food plant vendors each, for a total of 12 individual fresh food plant vendors. The market areas were selected by their location in three separate areas of the Chinatown district. Plants specimens were collected in the Chinatown market areas to supplement previous research in the area (Nguyen 2006) and to contribute to the voucher specimen collection of food plants in Chinatown, Honolulu at the Herbarium of the University of Hawai i at Manoa (HAW). The mainstream markets are coded as M1, M2, and M3. The Chinatown market areas are coded C1, C2, and C3. Individual vendors within the Chinatown market areas are coded with the Chinatown market area designation, followed by the first letter of the vendor name (i.e., C1-P, C1-Y, C1-5, C1-M, C1-H, C2-L, C2-G, C3-C, C3-I, C3-S, C3-R, and C3-7).

(2) Microsoft Excel and SPSS 12.0 (Apache Software Foundation 1989-2003) were used to organize raw data and calculate descriptive statistics of the food plant richness between the mainstream supermarkets and the Chinatown market areas, among the mainstream and individual vendors within Chinatown market areas, and to compare the different food plant forms found in the markets. The mainstream and Chinatown market areas represented to two independent samples, and the parametric assumptions were not met due to the small sample size, therefore the Mann-Whitney test was used to compare the means of food plant and form richness in the samples.

(3) Agglomerate cluster analysis in the Community Analysis Package (CAP) (Seaby et al. 2004) program was used to conduct the vegetation analyses of the markets and market areas. The basic process is that all the samples (columns) start as separate groups that are joined together one at a time until a single group is formed using Ward's, or minimum variance or error sums of squares clustering method for determining groups to be joined. At each iteration, all possible pairs of groups are compared and the two groups chosen for fusion are those which will produce a group with the lowest variance. The correlation coefficient calculated to measure the association between the groups was Jaccard's Coefficient for dissimilarity (DJ), where $D J=0$ indicates identical groups and the maximum positive value equals complete dissimilarity. Jaccard's Co- efficient, which is based on species presence only, was chosen to discount a similarity based on the species present and species that are not present which two groups would have in common (Causton 1988:87).

\section{Results}

Two-hundred ninety-three (293) fresh food plants were recorded (Appendix 1) in the mainstream supermarkets and Chinatown markets combined. The mainstream supermarkets were more rich in varieties of food plants than the Chinatown market area (mean \pm s, $144 \pm 21$ vs. $95 \pm$ 23, $p=0.05$, Mann-Whitney $U$ test). These market areas have in common $7 \%(21 / 293)$ of the entire plant list. Separately, the mainstream supermarkets have 35\% (78/224 mainstream total) of food plants in common, compared to Chinatown market areas of 24\% (36/151 Chinatown total). However, when the individual vendors that make up the Chinatown market areas are compared to each other, there is only a $1 \%(2 / 151$ Chinatown total) similarity. The two food plants that are available from every mainstream market and individual Chinatown vendor surveyed are onions (Allium cepa L.) and garlic (Allium sativum L). Their use by a wide rage of cultures and ethnic cuisines, as well as their ease of storage, could account for their common presence. . . Vendors have told us that "everyone uses [these]," and customers buy them when shopping for other food items. This convenient shopping is apparent in that onions and garlic were often placed near the cash register of Chinatown vendors. Ginger (Zingiber officionale Roscoe) was found in every mainstream market and all but one Chinatown vendor stand. The near ubiquitous presence of ginger can also be accounted for by its ease of long-term storage and its use in many different ethnic cuisines (Simoons 1991, Solomon 1996, Staples \& Kristiansen 1999).

\section{Food Plant Taxa}

There are 42 plant families, as well as fungi, represented in the entire survey. Fungi are found in all three Mainstream and Chinatown market areas. Eleven (26\%) of the plant families were found at all of the markets surveyed. These families are Alliaceae, Apiaceae, Araceae, Asteraceae, Brassicaceae, Curcurbitaceae, Fabaceae, Musaceae, Rutaceae, Solanaceae, and Zingiberaceae. The mainstream markets have 21 families in common ( $50 \%$ of the total number of plant families). Three of which are not present in the Chinatown markets: Asparagaceae, (i.e., asparagus [Asparagus officinalis L.]), Ericaceae (i.e., blueberries [Vaccinium sp. L.]), and Vitaceae (i.e., grapes [Vitis vinifera L.]). Although they are absent, grapes and asparagus have spread into Asian cuisines, while blueberries are less popular (Simoons 1991, Solomon 1996).

The Chinatown market areas have 17 plant families in common (39\% of the total number of plant families). Three 
families common to the Chinatown market areas are not present in any of the mainstream markets: Arecaceae (i.e., coconut [Cocos nucifera L.]), Malvaceae (i.e., okra [Abelmoschus esculentus (L.) Moench] and Jew's mallow [Corchorus olitorius L.]), and Sapotaceae (i.e., star-apple [Chrysophyllum cainito L.]). These species represent food plants that are characteristic to local ethnic cuisines (e.g., okra and Jew's mallow sold by Filipino vendors) and that are locally grown and harvested (Staples \& Herbst 2005).

The Chinatown market areas each have at least one unique family that is not present at any other market; none of the mainstream markets have any unique families. C1 has 6 unique families (14\% of the total number of families): Scrophulariaceae (i.e., rice-paddy herb [Limnophila chinensis (Lam.) Yamazaki]), Sapindaceae (i.e., Iongan [Dimocarpus longan Lour.] and rambutan [Nephelium lappaceum L.]), Polygonaceae (i.e., Vietnamese mint [Persicaria odorata (Lour.) Soják]), Moraceae (i.e., kamansi, a seeded breadfruit [Artocarpus camansi Blanco] and jackfruit [Artocarpus heterophyllus Lam.]), Iridaceae (i.e., "red garlic," [Eleutherine subaphylla Herbert]), and Clusiaceae (i.e., mangosteen [Garcinia mangostana L.]). Euphorbiaceae (i.e., cassava [Manihot esculenta Crantz]) is found only in C2. C3 has one unique family: Moringaceae (i.e., the leaves and fruit of the drumstick tree [Moringa oleifera Lam.]). All of these food plants are known to be used in Asian ethnic cuisines found in Hawai'i or are fruits of warm climates that are locally grown and harvested. For example, $M$. oleifera trees are naturalized in Hawai'i and the leaves and fruit, known as "drumstick pods," are used especially in Filipino cooking (Corum 2000).

\section{Analysis by Food Plant Form}

The majority of food plants in both the Mainstream (M) and Chinatown (C) market areas are fruits, both sweet (fruit-sweet) and those used as "vegetables" (fruit-veg), and other vegetative parts used as vegetables (leafy-veg) (Table 1). The Mann-Whitney test analysis of the different

Table 1. Average number of food plants present in different forms in Mainstream and Chinatown market areas. Significance levels obtained using the Mann-Whitney test. NA: Indicates that the presence of these categories was too low for testing. * Significance at the $p=0.05$ level.

\begin{tabular}{|l|l|c|l|l|l|l|}
\hline \multirow{2}{*}{$\begin{array}{l}\text { Food Plant } \\
\text { Form }\end{array}$} & \multicolumn{2}{|l|}{ Mainstream markets } & \multicolumn{2}{l|}{ Chinatown markets } & \multirow{2}{*}{} \\
\cline { 2 - 6 } & Number & Mean (Std) & Number & Mean (Std) & P value \\
\hline 1 & Aromatic & 3 & $8.3(0.6)$ & 3 & $7.3(5.5)$ & NA \\
\hline 2 & Flower & 3 & $0.7(0.6)$ & 3 & $2.3(2.1)$ & 0.37 \\
\hline 3 & Fruit-Sweet & 3 & $44.0(3.6)$ & 3 & $20.0(7.8)$ & $0.05^{*}$ \\
\hline 4 & Fruit-Veg & 3 & $33.0(8.9)$ & 3 & $28.3(6.5)$ & 0.51 \\
\hline 5 & Fungi & 3 & $4.7(0.6)$ & 3 & $1.3(0.6)$ & NA \\
\hline 6 & Leafy-Veg & 3 & $30.0(8.7)$ & 3 & $19.7(3.2)$ & $<0.05^{*}$ \\
\hline 7 & Root & 3 & $23.0(5.0)$ & 3 & $15.7(5.1)$ & 0.13 \\
\hline
\end{tabular}

forms of food plants indicates the Mainstream markets offers significantly more sweet fruits and leafy vegetables than the Chinatown markets. For the fungi category, this difference is probably an artifact caused by the small sample size.

\section{Vegetation Analysis}

A vegetation analysis of the presence of food plants in the 6 main markets (M1, M2, M3, C1, C2, C3) using Agglomerate Cluster Analysis (Ward's, Jaccard's +/-) shows that there is an association (i.e., less dissimilarity) among the three Mainstream (M1, M2, M3) and three Chinatown $(\mathrm{C} 1, \mathrm{C} 2, \mathrm{C} 3)$ markets areas (Figure 1). In the case of the Chinatown markets, C3, the Jaccard's coefficient for dissimilarity (DJ) is higher than DJ for $\mathrm{C} 1$ and $\mathrm{C} 2$. This reflects the cultural specificity of the food plants in the $\mathrm{C} 3$ area. We discuss C3 in greater detail in the next analysis of the Chinatown market analyzed as separate vendors.

The agglomerate cluster analysis was re-run comparing all of the markets individually (i.e., three Mainstream market areas and the 12 individual vendors that make up the three larger Chinatown market areas). This analysis (Figure 2) also grouped the three Mainstream market areas; in addition, the Chinatown vendors C1-Y, C1-M and C2-G. These are among the larger vendors in the Chinatown market areas (sum food plants, $\Sigma f=44,41,75$, respectively) and would be closest in comparison to the generalist Mainstream markets. While C2-G is the largest of all the individual vendors in the Chinatown survey, vendors C1-P and C3-7 are richer in food plants $(\Sigma f=63,48$, respectively) than $\mathrm{C} 1-\mathrm{Y}$ and $\mathrm{C} 1-\mathrm{M}$. We believe that the grouping of $\mathrm{C} 1-\mathrm{Y}, \mathrm{C} 1-\mathrm{M}$ and $\mathrm{C} 2-\mathrm{G}$, is a combination of their richness and an association of food plants common to the three vendors exclusively for the Chinatown areas. These include mung bean sprouts (Vigna radiata (L.) R. Wilczek) and potato (Solanum tuberosum L.), and other examples that include two of the three vendors, including celery (Apium graveolens L.), lettuce (Lactuca sativa L.), and taro (Colocasia esculenta (L.) Schott).

The same analysis also clustered the vendors that identified as Filipino, and those that were Vietnamese, based on particular associations of food plants. These are identified as the cultural plant assemblages that are characteristic for that ethnic or cultural vendor. In our survey, all of the Filipino vendors (C1-P, C3-C, C3-R, C3-I, and C3-7) have in common the yard-long beans (Vigna unguiculata subsp. sequipedalis (L.) Verdc.), okra (Abelmoschus esculentus (L.) Moench), small bitter melon 


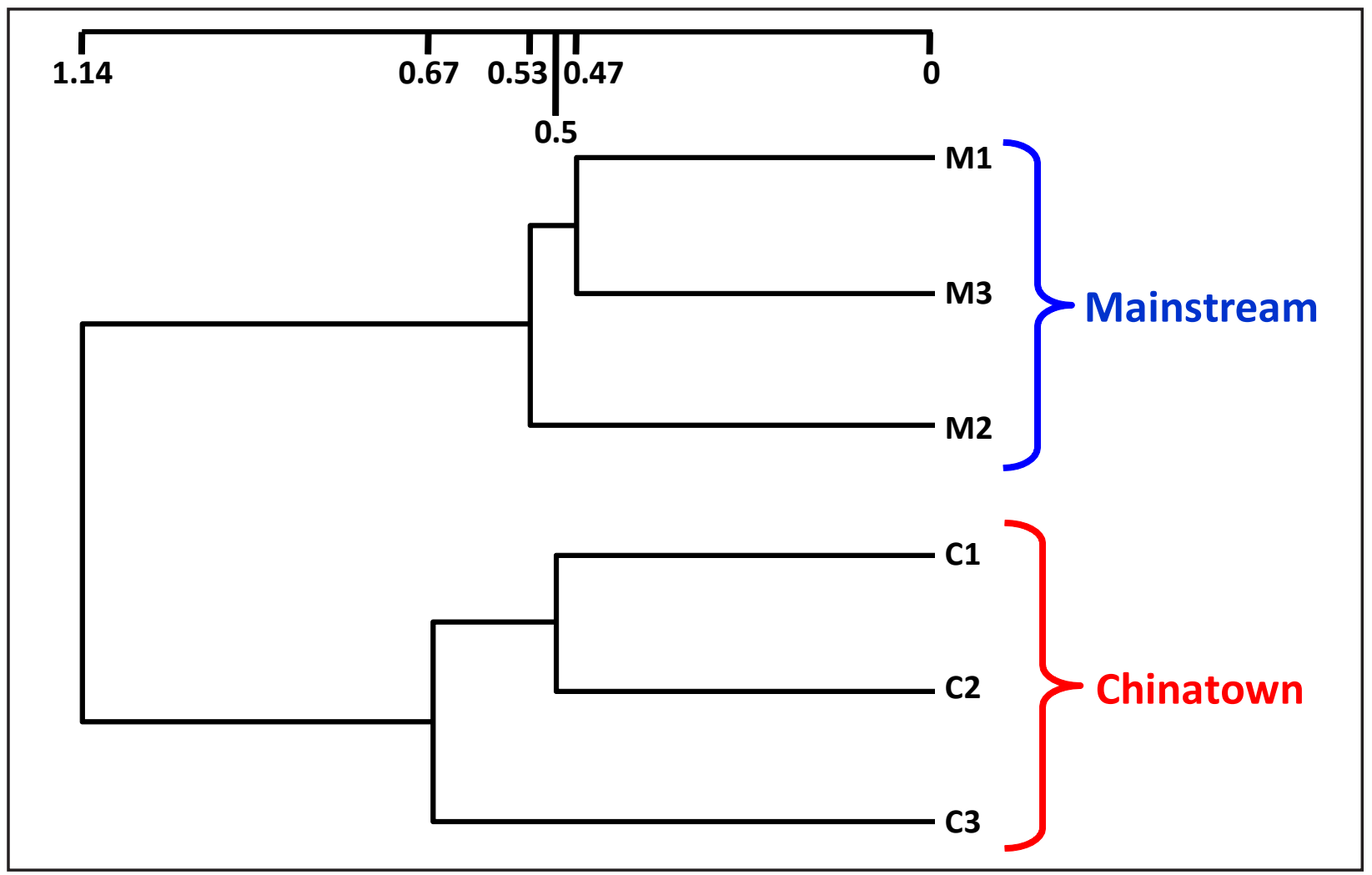

Figure 1. Agglomerate Cluster Analysis shows the similarity shared between the Mainstream markets and Chinatown markets areas resulting in two distinct groupings. The number scale shows Jaccard's Coefficient for dissimilarity (DJ), where DJ.=0 indicates identical groups and the maximum positive value equals complete dissimilarity.

(Momordica charantia L.), and a long, thin purple eggplant variety (Solanum melongena L.). These food plants, along with tomatoes (Lycopersicon esculentum L.) that are very common in the markets, are used to make the traditional Filipino vegetable stew, pinacbet (Corum 2000). The importance of this cultural plant assemblage is evident in it being supplied in different forms (i.e., (1) whole and found in adjacent bins, (2) portioned and grouped together near the cash register, and (3) chopped into ready to cook pieces in one package). Other plants that grouped in the analysis and that some of these Filipino vendors sold are specifically associated with Filipino foods. These Filipino cultural indicator plants include, malunggay (Filipino-Tagalog dialect) leaves and the drumstick pods of $M$. oleifera (previously described as a unique representative in the C3 area), the young leafy shoots of bitter melon, yardlong beans, chayote (Sechium edule (Jacq.) Swartz), and a variety of "Japanese" or "Kapocha/Kabocha" pumpkin called "Papaya Sweet" for its shape and flavor and specifically identified by the vendors as "Filipino pumpkin" ( $\mathrm{Cu}$ curbita moschata Duch. Ex Poir.).

Vietnamese vendors were identified by the presence of aromatic leafy food plants characteristic to Vietnamese cuisine. These Vietnamese cultural indicator plants include "Thai" basil (Ocimum basilicum L.), water mint (Mentha aquatica L.), lizard's tail herb (Houttuynia cordata Thunb.), rice-paddy herb (Limnophila chinensis subsp. aromatica (Lam.) Yamazaki), thorny coriander (Eryngium foetidum L.), Vietnamese mint (Persicaria odorata (Lour.) Soják), and though also found in other markets, cilantro (Coriandrum sativum L.). These Vietnamese vendors also had a slightly greater percentage of aromatics ( $9 \%$ and $11 \%)$ than the average found in both the mainstream (8\%) and Chinatown markets areas $(7 \%)$, but this sample size is too small to test for a difference from the market areas.

An additional group identified as "specialty fruit vendors" clustered in this analysis. The specialty vendor C3-S, identified as a specific ethnic fruit stand and vendor C1-5 supplies mostly sweet fruits (16:20 total food plants in C1-5) in the $\mathrm{C} 1$ market area.

\section{Discussion \& Conclusions}

This study provides updated and empirical data on the food plant richness of culturally diverse Honolulu, Hawai'i (U.S.). Mainstream supermarkets have a slightly greater richness of food plants than Chinatown market areas. A vegetation analysis approach enabled us to delineate the large Mainstream and Chinatown market areas as two distinct areas based on the available food plant varieties; 


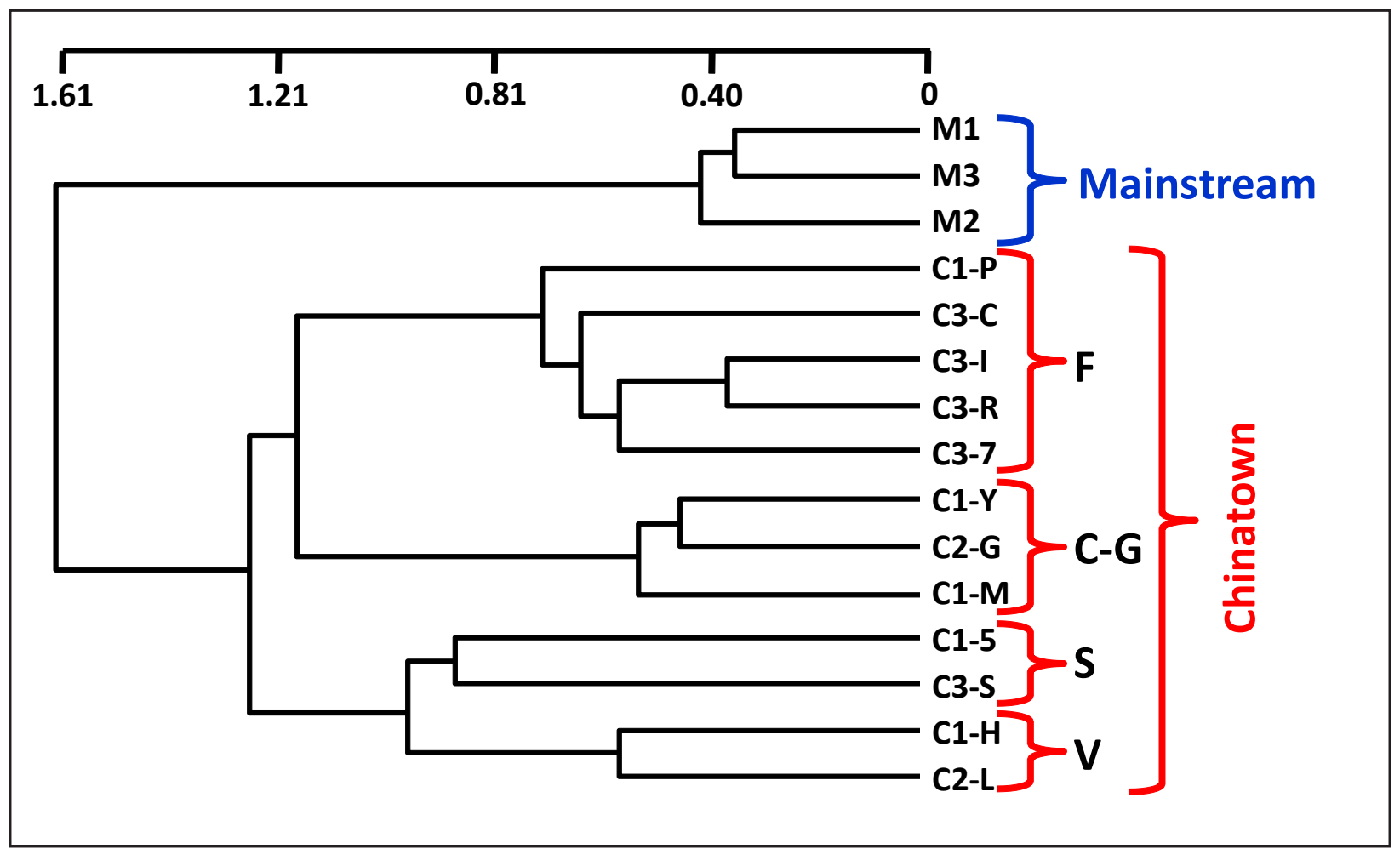

Figure 2. Agglomerate Cluster Analysis of Mainstream (M) and individual Chinatown market area vendors (C), that include Chinatown-generalists (C-G), Filipino (F), and Vietnamese (V) vendors. Specialty fruit vendors (S) are also clustered together. The number scale shows Jaccard's Coefficient for dissimilarity (DJ), where DJ.=0 indicates identical groups and the maximum positive value equals complete dissimilarity. Individual vendors within the Chinatown market areas are coded with the Chinatown market area designation, followed by the first letter of the vendor name (i.e., C1-P, C1-Y, C1-5, C1-M, C1-H, C2-L, C2-G, C3-C, C3-I, C3-S, C3-R, and C3-7).

and when analyzing the individual vendors that make up the Chinatown market areas, confirmed cultural and specialty markets based on the presence of cultural indicator food plants and their associated plant assemblages. Mainstream supermarkets can be viewed as "generalists," supplying a wide range of food plants to fill the needs of a diverse community. The Chinatown market areas and vendors can be considered "specialists."

We acknowledge the limitations of this study as a "snapshot" survey of the markets during the spring season of Hawai'i. A more comprehensive view of the markets in Honolulu may be attained with continued surveys throughout the calendar year. Although analyses conducted in this study shows the presence of ethnic "specialists" vendors, these designations are not always so strict. We have observed ethnic specialty vendors selling food plants associated with other ethnic and cultural groups, and there are food plants that are used by more than one group of people in similar and different manners.

Our study serves to connect ethnobotanical research in a meaningful way to urban communities. Wang and Lo (2007) found that ethnic affinity affects immigrant choice of market venue more strongly than economic rationali- ties. Culture and economy are deeply intertwined with each other in immigrant consumption behavior. Our study supports this by demonstrating that cultural assemblages of food plants available in the culturally affiliated Chinatown vendors are far more present and available than in the mainstream grocery stores in the same area of accessibility. This study does not directly address issues of community and cultural vigor, but its results does show that ethnic communities influence food plant availability in an urban setting. This, in turn, is a reflection of ethnic community cultural and nutritional health.

We posed the research question: To what extent do these mainstream supermarkets provide the same food plants available in the ethnic markets? Our results go beyond answering this question and the identification of generalist or specialty markets, and cultural assemblages, when interpreted with regard to ethnic and immigrant community vitality in a multicultural urban setting such as Honolulu.

Garibaldi and Turner (2004) found that identification and analysis of cultural indicator species such as cultural food assemblages can provide a starting point for further analysis of cultural resistance in the face of change, and that loss of access to such species can symbolize a more dra- 


\section{Nguyen et al. - Vegetation Analysis of Urban Ethnic Markets Shows Supermarket Generalists and Chinatown Ethnic-specialist Vendors}

matic loss of language and culture (Garibaldi \& Turner 2004).

Cristancho and Vining (2004) found that Cultural Keystone Species designates plant and animal species whose existence and symbolic value are essential to the stability of a culture over time. This could be particularly relevant within multicultural, urban communities in order to retain and express culture. Further, cultures living in urban environments do develop notions of Cultural Keystone Species (Cristancho \& Vining 2004). We find that a comparable value of cultural food and plant assemblages reflect a certain cultural keystone species aspect. Further, patronizing ethnic stores is a way of maintaining a sense of belonging to an ethnic community, and ethnic identity plays a critical role in the choice between ethnic and mainstream businesses (Wang \& Lo 2007). Our findings when combined with those of Wang \& Lo (2007), Cristancho and Vining, 2004, and Garibaldi and Turner (2004) demonstrate the ethnic markets reflects ethnic communities in an urban setting through the assemblages of food plants that are culturally specific available in them.

As the cultural and ethnic diversity in the U.S. continues to grow, studies in urban ethnic market areas are imperative to gather empirical data to identify and study the biocultural diversity and implications of these sites. Based on this assumption and the analysis of our data it seems apparent that certain ethnic communities are thriving culturally in Honolulu. This information will be significant for understanding the dynamics of cultural food plant use that would be useful to local, non-governmental and governmental groups to access the needs and impact of the diverse population in the U.S.

\section{Literature Cited}

Apache Software Foundation. 1989-2003. SPSS 12.0 for Windows.

Bonk, S.K.F. 1993. The Farmer's Market is Cookin' in Hilo, Hawai i. Mountain View, Hawai i.

Camarota, S.A. 2005. Immigrants at Mid-Decade: A Snapshot of America's Foreign-Born Population in 2005. Center for Immigration Studies. Washington, D.C. www.cis. org/articles/2005/back1405.pdf

Carter, F. 1988. Exploring Honolulu's Chinatown. Bess Press, Honolulu.

Causton, D.R. 1988. An Introduction to Vegetation Analysis: Principles, practice and interpretation. Unwin Hyman Ltd., London.
Chung, H.L. \& J.C. Ripperton. 1929. Utilization and composition of oriental vegetables in Hawaii. Bulletin No. 60. Hawaii Agricultural Experiment Station, Honolulu.

Corum, A.K. 2000. Ethnic Foods in Hawaii. The Bess Press, Honolulu.

Cunningham, A.B. 2001. Applied Ethnobotany: People, wild plant use and conservation. Earthscan, London.

Cristancho, S. \& J. Vining. 2004. Culturally defined keystone species. Human Ecological Review 11:153-162.

Garibaldi, A. \& N. Turner. 2004. Cultural keystone species: Implications for ecological conservation and restoration. Ecology and Society 9(3):1.

Kalcik, S. 1984. Ethnic foodways in America: Symbol and the performance of identity. Pp. 37-65 in Ethnic and Regional Foodways in the U.S. Edited by L.K. Brown \& K. Mussell. University of Tennessee Press, Knoxville.

Kendrick, S. 1999. Chinatown Food Walk. Honolulu StarBulletin Newspaper October 6, Features section.

Nguyen, M.T. 2003. Comparison of food plant knowledge between urban Vietnamese living in Vietnam and in Hawai i. Economic Botany 57:472-480.

Nguyen, M.T. 2005a. Bạc hà (Colocasia gigantea (Blume) Hook. f.) in the culinary history of Vietnamese-Americans. Economic Botany 59:185-196.

Nguyen, M.T. 2005b. Cultivated plant collections from market places. Ethnobotany Research and Applications 3:5-15.

Nguyen, M.T. 2006. Insertions and deletions: Evolution in the assemblage of Vietnamese food plants. Ethnobotany Research and Applications 4:175-202.

Nguyen, M.T. 2007. Community dynamics and functional stability: a recipe for culinary continuity and adaptation. Economic Botany 61:337-346.

Pemberton, R.W. \& N.S. Lee. 1996. Wild food plants in South Korea; market presence, new crops, and exports to the United States. Economic Botany 50:57-70.

Porterfield Jr., W.M. 1951. The principal Chinese vegetable foods and food plants of Chinatown markets. Economic Botany 5:3-37.

Rozin, E. 1973. The Flavor-Principal Cookbook. Hawthorne Books, Inc., New York. 
Salick, J., A. Byg, A. Amend, B. Gunn, W. Law \& H. Schmidt. 2006. Tibetan medicine plurality. Economic Botany 60:227-253.

Seaby, R., P. Henderson, J. Prendergast \& R. Somes. 2004. Community Analysis Package 3.0. Pisces Conservation Ltd., Hampshire, England.

Simoons, F.J. 1991. Food in China, a cultural and historical inquiry. CRC Press, Inc, Boca Raton.

Solomon, C. 1996. Encyclopedia of Asian Food. Periplus Editions, Boston.

Staples, G.W. \& D.R. Herbst. 2005. A Tropical Garden Flora: Plants cultivated in the Hawaiian Islands and other tropical places. Bishop Museum Press, Honolulu.

Staples, G.W. \& M.S. Kristiansen. 1999. Ethnic Culinary Herbs: A guide to identification and cultivation in Hawai i. University of Hawai'i Press, Honolulu.

Tan, T. 2003. Asian Cook. Laurel Glen, San Diego.
Wang, L. \& L. Lo. 2007. Immigrant grocery-shopping behavior; ethnic identity versus accessibility. Environment and Planning A 39:684-699.

Wester, L.L. \& D. Chuensanguansat. 1994. Adoption and abandonment of Southeast Asian food plants. Pp. 83-91 in People-Plant Relationships: Setting Research Priorities. Edited by J. Flagler \& R. P. Poincelot. The Haworth Press, Inc., Philadelphia.

Whitaker, T.W. \& H.C. Cutler. 1966. Food plants in a Mexican market. Economic Botany 20:6-16.

Williams, V.L., K. Balkwill \& E. T.F. Witkowski. 2000. Unraveling the commercial market for medicinal plants and plant parts of the Witwatersand, South Africa. Economic Botany 54:310-327.

Yim, S.F. 1998. Roaming Honolulu's Chinatown: Neighborhood ustles with sights, sounds, and memories. Car \& Travel Hawaii edition:4-5.

You-Kai, X., T. Guo-Da, L. Hong-Mao, Y. Kang-La \& D. Xiang-Sheng. 2004. Wild vegetable resources and market survey in Xishuangbanna, Southwest China. Economic Botany 58:647-667. 
Nguyen et al. - Vegetation Analysis of Urban Ethnic Markets Shows

Supermarket Generalists and Chinatown Ethnic-specialist Vendors

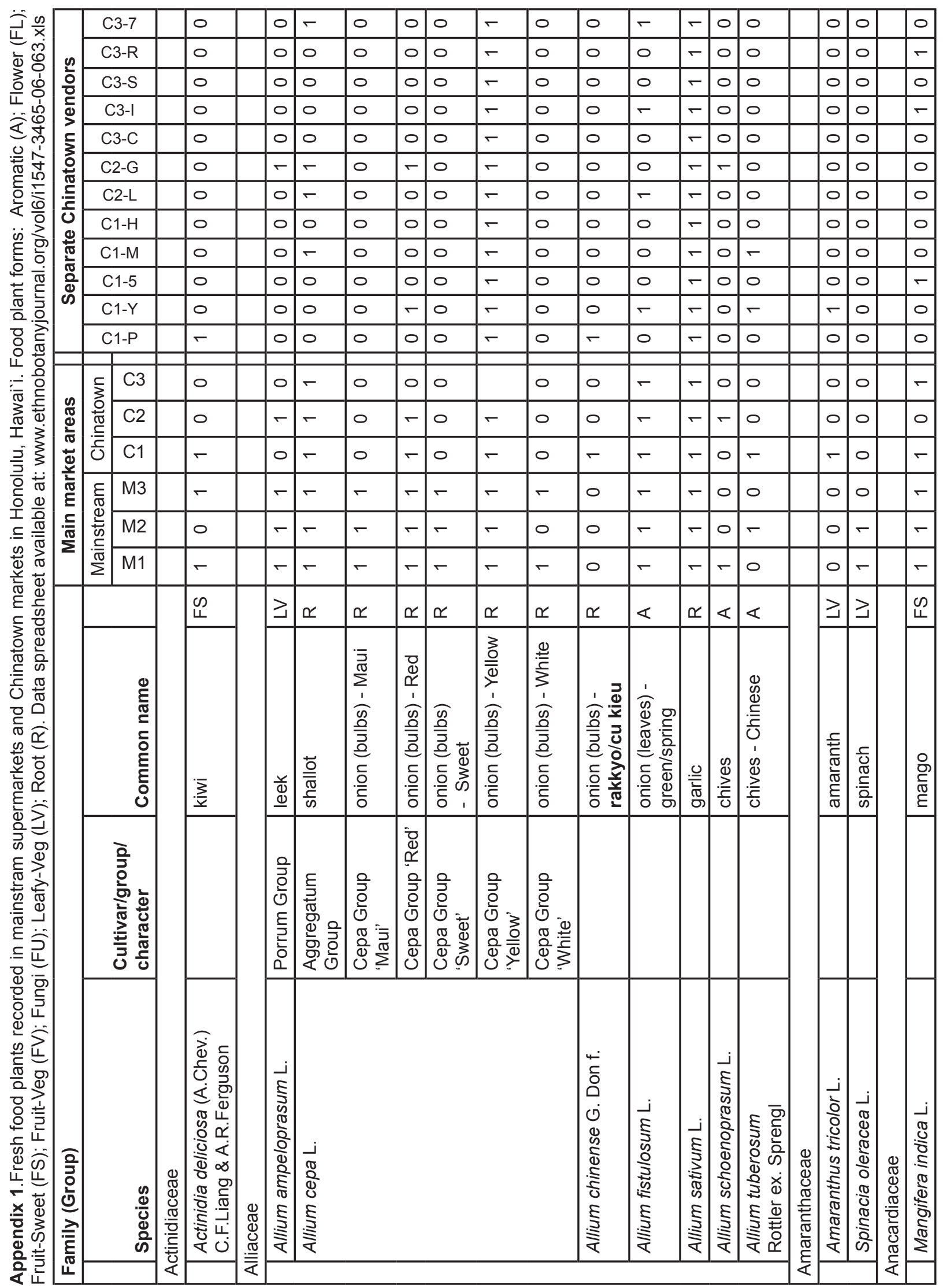




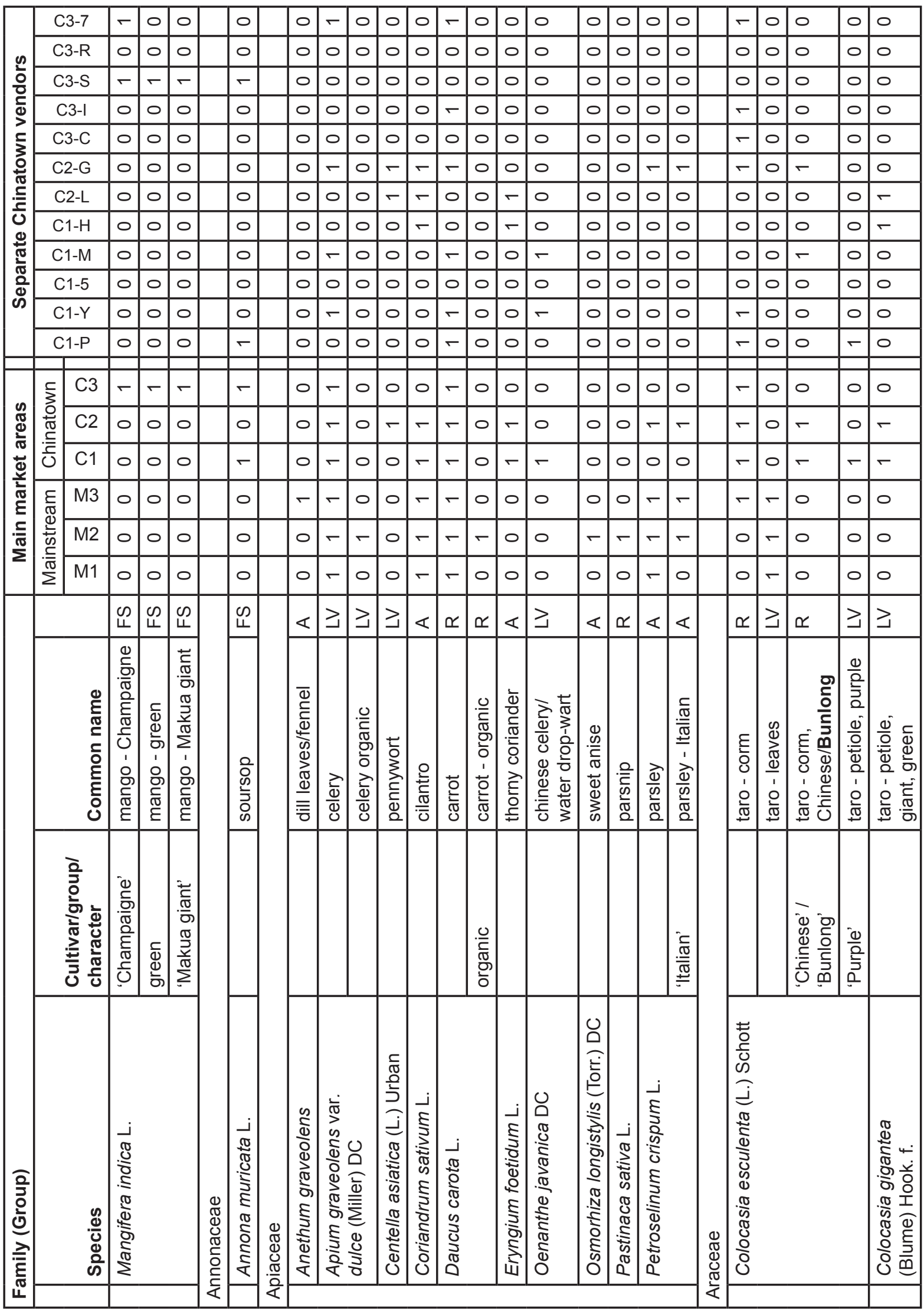


Supermarket Generalists and Chinatown Ethnic-specialist Vendors

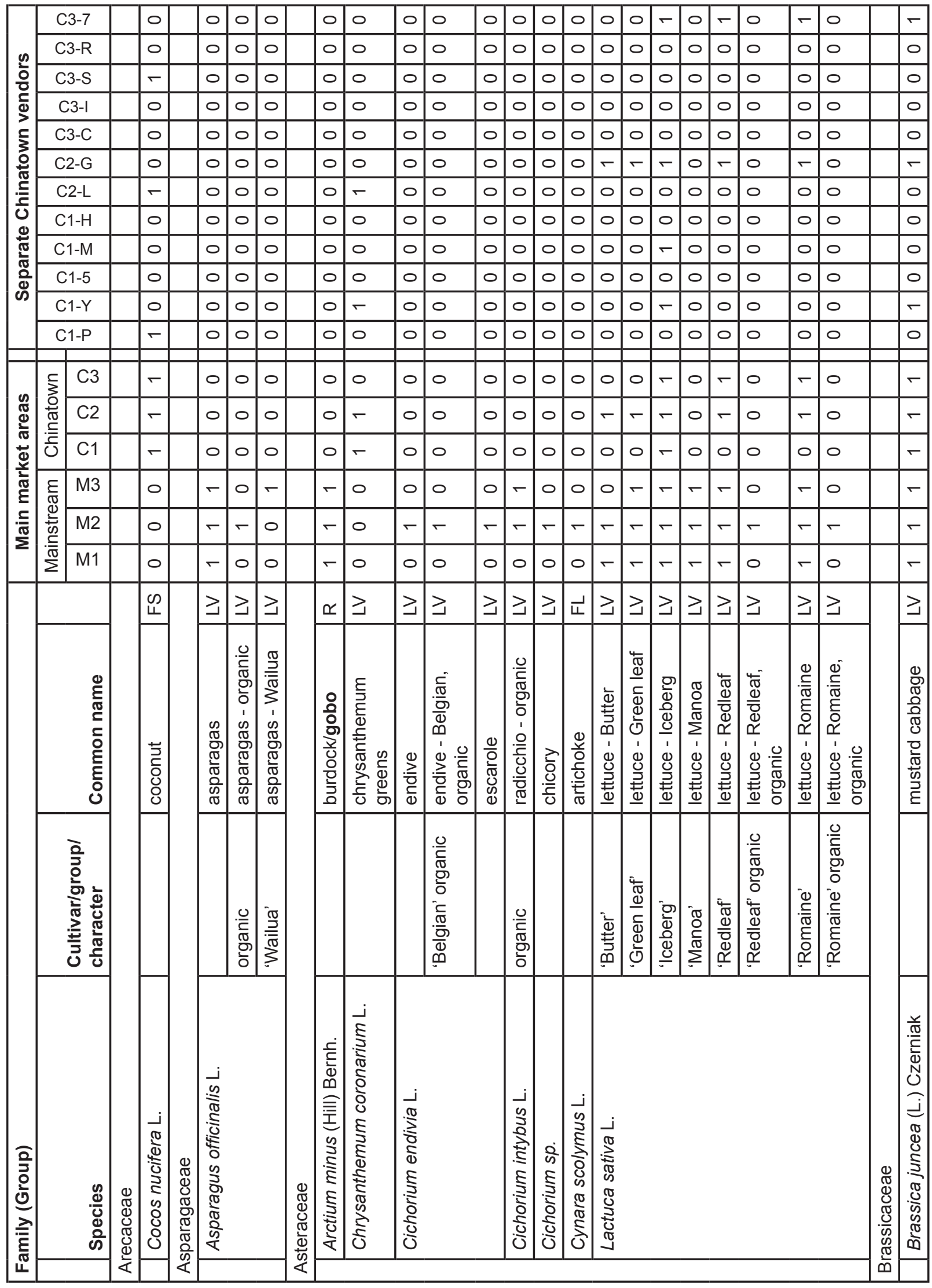




\begin{tabular}{|c|c|c|c|c|c|c|c|c|c|c|c|c|c|c|c|c|c|c|c|c|c|}
\hline \multirow{12}{*}{ 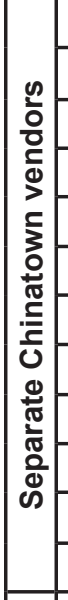 } & C3-7 & 0 & 0 & 0 & 0 & \begin{tabular}{c|c}
- & $c$ \\
\end{tabular} & \begin{tabular}{l|l|}
0 & 0 \\
\end{tabular} & - & 0 & \begin{tabular}{l|l}
$\circ$ & 0 \\
\end{tabular} & \begin{tabular}{l|l|}
0 & 0 \\
\end{tabular} & - & 0 & $r$ & 0 & 0 & \begin{tabular}{l|l}
0 & 0
\end{tabular} & \begin{tabular}{l|l|l}
0 & - & 0 \\
\end{tabular} & \begin{tabular}{l|l}
0 & 0
\end{tabular} & & 0 \\
\hline & C3-R & 0 & 0 & 0 & 0 & 0 & \begin{tabular}{l|l|}
0 & 0
\end{tabular} & 0 & 0 & 0 & \begin{tabular}{l|l|}
0 & 0
\end{tabular} & $r$ & 0 & 0 & 0 & 0 & \begin{tabular}{l|l}
0 & 0
\end{tabular} & $0 \mid-c$ & 0 & & 0 \\
\hline & C3-S & 0 & 0 & 0 & 0 & \begin{tabular}{l|l}
$\circ$ & 0 \\
\end{tabular} & \begin{tabular}{l|l|}
0 & 0 \\
\end{tabular} & 0 & 0 & \begin{tabular}{|l|l|}
$\circ$ & 0 \\
\end{tabular} & \begin{tabular}{l|l|}
0 & 0 \\
\end{tabular} & 0 & 0 & 0 & 0 & 0 & \begin{tabular}{l|l}
0 & 0 \\
\end{tabular} & \begin{tabular}{l|l|l|}
0 & 0 & 0 \\
\end{tabular} & \begin{tabular}{l|l}
0 & 0 \\
\end{tabular} & & 0 \\
\hline & C3-I & 0 & 0 & 0 & 0 & 0 & \begin{tabular}{l|l|l|l|l|l}
0 & 0
\end{tabular} & - & 0 & 100 & \begin{tabular}{l|l|l|l|l|l|l}
0 & 0
\end{tabular} & 0 & 0 & 0 & 0 & 0 & \begin{tabular}{l|l}
0 & 0
\end{tabular} & 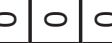 & \begin{tabular}{l|l}
0 & 0
\end{tabular} & & 0 \\
\hline & C3-C & 0 & 0 & 0 & 0 & \begin{tabular}{l|l} 
& 0 \\
\end{tabular} & \begin{tabular}{l|l|}
0 & 0 \\
\end{tabular} & 0 & 0 & \begin{tabular}{|l|l|}
0 & 0 \\
\end{tabular} & \begin{tabular}{l|l|}
0 & 0 \\
\end{tabular} & 0 & 0 & 0 & 0 & 0 & \begin{tabular}{l|l}
0 & 0
\end{tabular} & \begin{tabular}{ll|l} 
& 0
\end{tabular} & $\begin{aligned}- & 0\end{aligned}$ & & 0 \\
\hline & C2-G & 0 & 0 & 0 & 이 & $-c$ & \begin{tabular}{l|l}
0 & -1 \\
\end{tabular} & - & 0 & $\begin{array}{lll}0 & 0 \\
\end{array}$ & \begin{tabular}{l|l|}
0 & 0 \\
\end{tabular} & - & - & $r$ & 0 & 0 & \begin{tabular}{l|l}
0 & 0 \\
\end{tabular} & \begin{tabular}{l|l|l}
0 & - & 0
\end{tabular} & \begin{tabular}{l|l}
0 & -
\end{tabular} & & 0 \\
\hline & C2-L & - & 0 & 0 & 0 & 0 & 0.0 & 0 & 0 & 1010 & \begin{tabular}{l|l|l|l|l|l|l} 
& 0
\end{tabular} & 0 & 0 & 0 & 0 & 0 & 0 & $0 \mid-c$ & \begin{tabular}{l|l}
0 & 0
\end{tabular} & & 0 \\
\hline & $\mathrm{C} 1-\mathrm{H}$ & 0 & 0 & 0 & 0 & 0 & 0.0 & 0 & 0 & 1010 & 0.0 & 0 & 0 & 0 & 0 & 0 & 0 & $0|0| c$ & \begin{tabular}{l|l}
0 & 0
\end{tabular} & & 0 \\
\hline & C1-M & 0 & 0 & 0 & 0 & \begin{tabular}{l|l} 
& 0 \\
\end{tabular} & \begin{tabular}{l|l|}
0 & 0 \\
\end{tabular} & - & 0 & \begin{tabular}{|l|l|}
0 & 0 \\
\end{tabular} & \begin{tabular}{l|l|}
0 & 0 \\
\end{tabular} & 0 & 0 & $r$ & 0 & 0 & \begin{tabular}{|l|l|}
0 & 0 \\
\end{tabular} & \begin{tabular}{l|l|l}
0 & 0
\end{tabular} & \begin{tabular}{l|l}
0 & -
\end{tabular} & & 0 \\
\hline & C1-5 & 0 & 0 & 0 & 0 & $0 \mid c$ & \begin{tabular}{l|l|}
0 & 0
\end{tabular} & 0 & 0 & \begin{tabular}{l|l}
0 & 0
\end{tabular} & \begin{tabular}{l|l|}
0 & 0
\end{tabular} & 0 & 0 & 0 & 0 & 0 & \begin{tabular}{l|l}
0 & 0
\end{tabular} & \begin{tabular}{l|l|l}
0 & 0 & 0
\end{tabular} & 0 & & $r$ \\
\hline & C1-Y & 0 & 0 & 0 & \begin{tabular}{l|l} 
\\
\end{tabular} & \begin{tabular}{l|c} 
& \\
\end{tabular} & \begin{tabular}{l|l|}
0 & - \\
\end{tabular} & - & 0 & \begin{tabular}{|l|l|l|}
0 & 0 \\
\end{tabular} & \begin{tabular}{l|l|}
0 & 0 \\
\end{tabular} & - & - & 0 & 0 & 0 & \begin{tabular}{l|l}
0 & 0 \\
\end{tabular} & \begin{tabular}{l|l|l}
0 & 0 & 0
\end{tabular} & \begin{tabular}{l|l}
0 & 0
\end{tabular} & & 0 \\
\hline & C1-P & 0 & 0 & 0 & 0 & \begin{tabular}{l|l}
0 & $c$
\end{tabular} & \begin{tabular}{l|l|}
0 & 0 \\
\end{tabular} & - & 0 & \begin{tabular}{l|l}
0 & 0 \\
\end{tabular} & \begin{tabular}{l|l|}
0 & 0 \\
\end{tabular} & - & 0 & 0 & 0 & 0 & \begin{tabular}{l|l}
0 & 0 \\
\end{tabular} & \begin{tabular}{l|l|l}
0 & - & - \\
\end{tabular} & \begin{tabular}{r|l}
- & 0 \\
\end{tabular} & & 0 \\
\hline \multirow{6}{*}{ 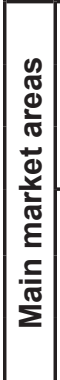 } & 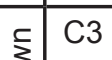 & 0 & 0 & 0 & 0 & $-c$ & 0.0 & - & 0 & 1010 & 0.0 & - & 0 & $r$ & 0 & 0 & 0 & $0 \mid-$ & -0 & & 0 \\
\hline & $\begin{array}{ll}\stackrel{0}{\pi} & \mathrm{C} 2\end{array}$ & - & 0 & 0 & 0 & $-c$ & \begin{tabular}{l|l|}
0 & - \\
\end{tabular} & - & 0 & \begin{tabular}{l|l}
0 & 0 \\
\end{tabular} & \begin{tabular}{l|l|}
0 & 0 \\
\end{tabular} & - & - & - & 0 & 0 & \begin{tabular}{l|l}
0 & 0
\end{tabular} & $0-0$ & \begin{tabular}{l|l}
0 & -
\end{tabular} & & 0 \\
\hline & $\begin{array}{lll}\bar{c} & \mathrm{C} 1\end{array}$ & 0 & 0 & 0 & 0 & 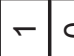 & \begin{tabular}{l|l|}
0 & -
\end{tabular} & - & 0 & 0 & \begin{tabular}{l|l|}
0 & 0
\end{tabular} & - & - & - & 0 & 0 & \begin{tabular}{l|l}
0 & 0
\end{tabular} & $0-1$ & $-F$ & & $r$ \\
\hline & \begin{tabular}{l|l}
\multirow{\sigma}{E}{} & M3
\end{tabular} & 0 & - & 0 & 0 & $\begin{array}{lll}- & c \\
\end{array}$ & \begin{tabular}{l|l|}
0 & - \\
\end{tabular} & - & 0 & $-c$ & \begin{tabular}{l|l|}
0 & 0 \\
\end{tabular} & - & $r$ & - & 0 & 0 & \begin{tabular}{l|l}
-1 & 0
\end{tabular} & $0-c$ & 0 o & & - \\
\hline & M2 & 0 & - & - & - & \begin{tabular}{l|l} 
& - \\
\end{tabular} & \begin{tabular}{l|l|}
- & - \\
\end{tabular} & - & 0 & -7 & \begin{tabular}{l|l|}
- & - \\
\end{tabular} & - & - & - & 0 & 0 & -10 & $0 \mid-c$ & 0 - & & - \\
\hline & $\sum^{\pi} \mid M 1$ & 0 & 0 & - & 0 & $-c$ & 0. & - & - & $-c$ & 0.0 & - & - & - & - & - & \begin{tabular}{l|l} 
& -
\end{tabular} & $--c$ & 0 o & & - \\
\hline & & $\geq$ & $\geq$ & $\geq$ & $\geq$ & $\geq 1$ & $\geq \geq$ & $\geq$ & $\geq$ & $\geq \geq$ & $\geq \geq$ & $\geq$ & 3 & $\geq$ & $\propto$ & 3 & 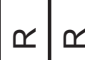 & 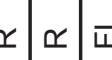 & $\vec{\sqcup}$ & & $\stackrel{\infty}{\rightleftarrows}$ \\
\hline & 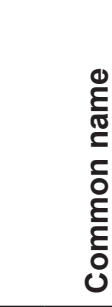 & 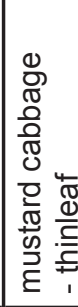 & $\mid \begin{array}{l}0 \\
\frac{0}{0} \\
\overline{0} \\
0 \\
0\end{array}$ & $\mid \begin{array}{l}\frac{\mathscr{N}}{\widetilde{N}} \\
\end{array}$ & 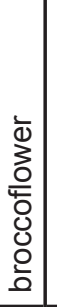 & 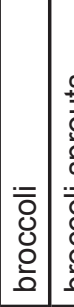 & 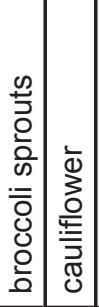 & 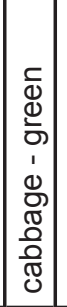 & 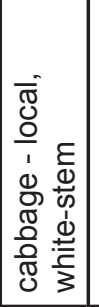 & 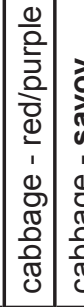 & 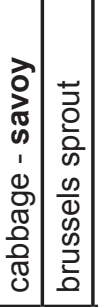 & 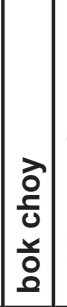 & 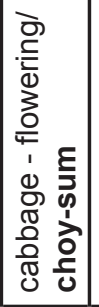 & 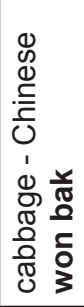 & $\stackrel{\circ}{\frac{O}{5}}$ & 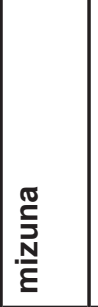 & 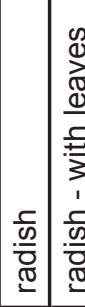 & 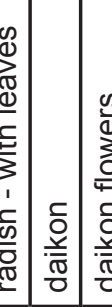 & 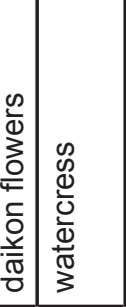 & & $\begin{array}{l}\frac{0}{0} \\
\frac{0}{0} \\
\frac{0}{0}\end{array}$ \\
\hline & 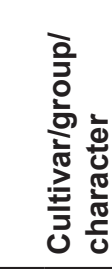 & 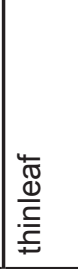 & $\begin{array}{l}\frac{0}{3} \\
0 \\
0 \\
\frac{0}{10} \\
\frac{\pi}{0} \\
\frac{0}{0} \\
\frac{0}{0} \\
0 \\
\frac{0}{4}\end{array}$ & & 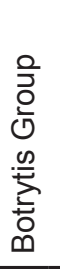 & & & 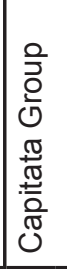 & & & 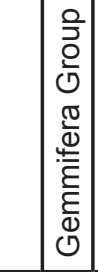 & 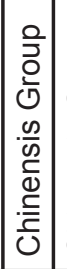 & 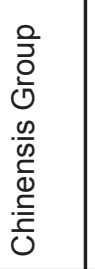 & 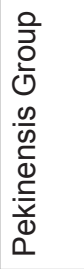 & 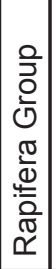 & & & 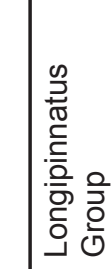 & & & \\
\hline 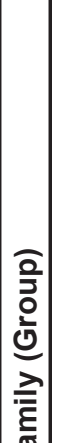 & $\begin{array}{l}\frac{\mathscr{0}}{0} \\
\Phi \\
\dot{\Xi}\end{array}$ & 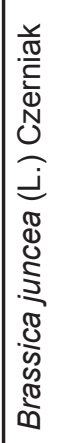 & 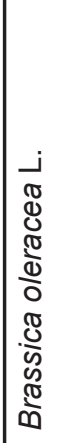 & & & & & & & & & 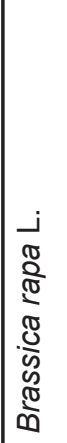 & & & & 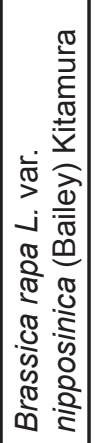 & 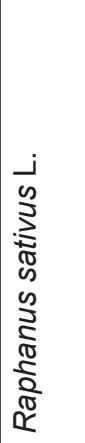 & & 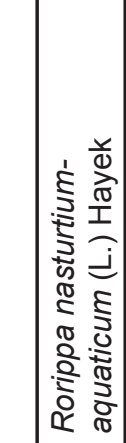 & 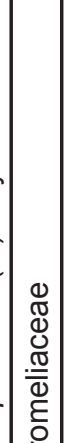 & 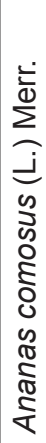 \\
\hline & & & & & & & & & & & & & & & & & & & & & \\
\hline
\end{tabular}


Nguyen et al. - Vegetation Analysis of Urban Ethnic Markets Shows

Supermarket Generalists and Chinatown Ethnic-specialist Vendors

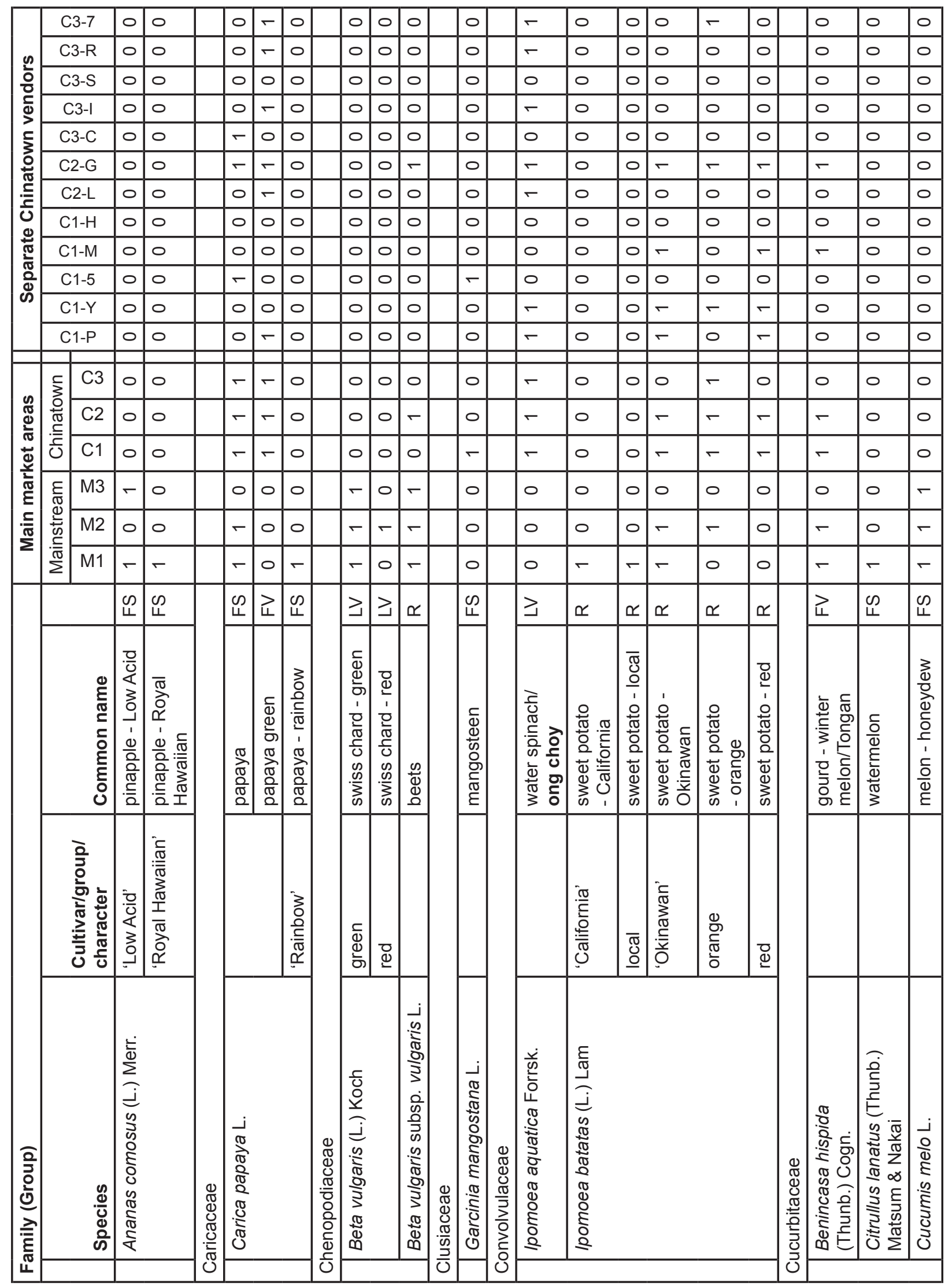

www.ethnobotanyjournal.org/vol6/i1547-3465-06-063.pdf 


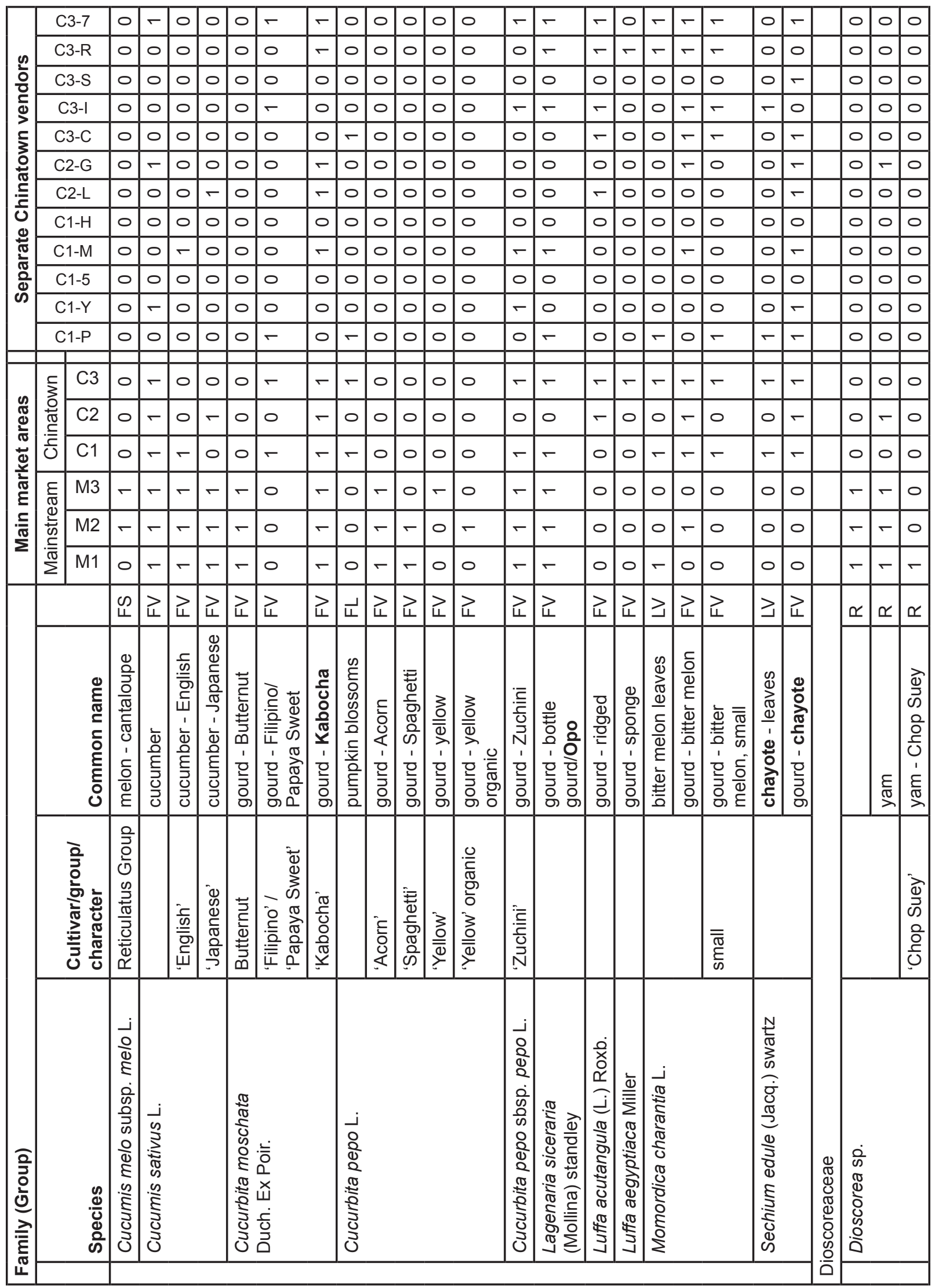


Supermarket Generalists and Chinatown Ethnic-specialist Vendors

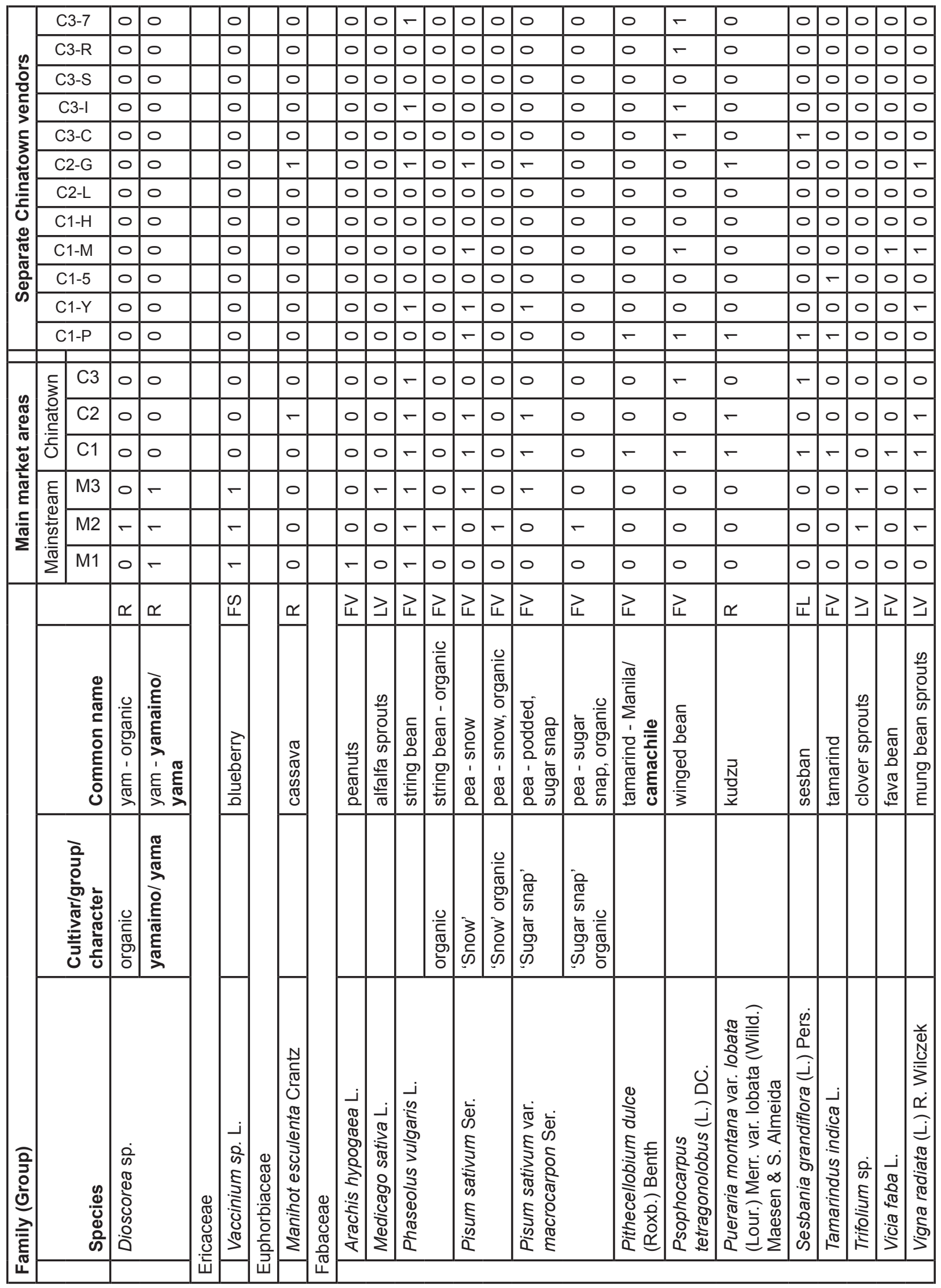




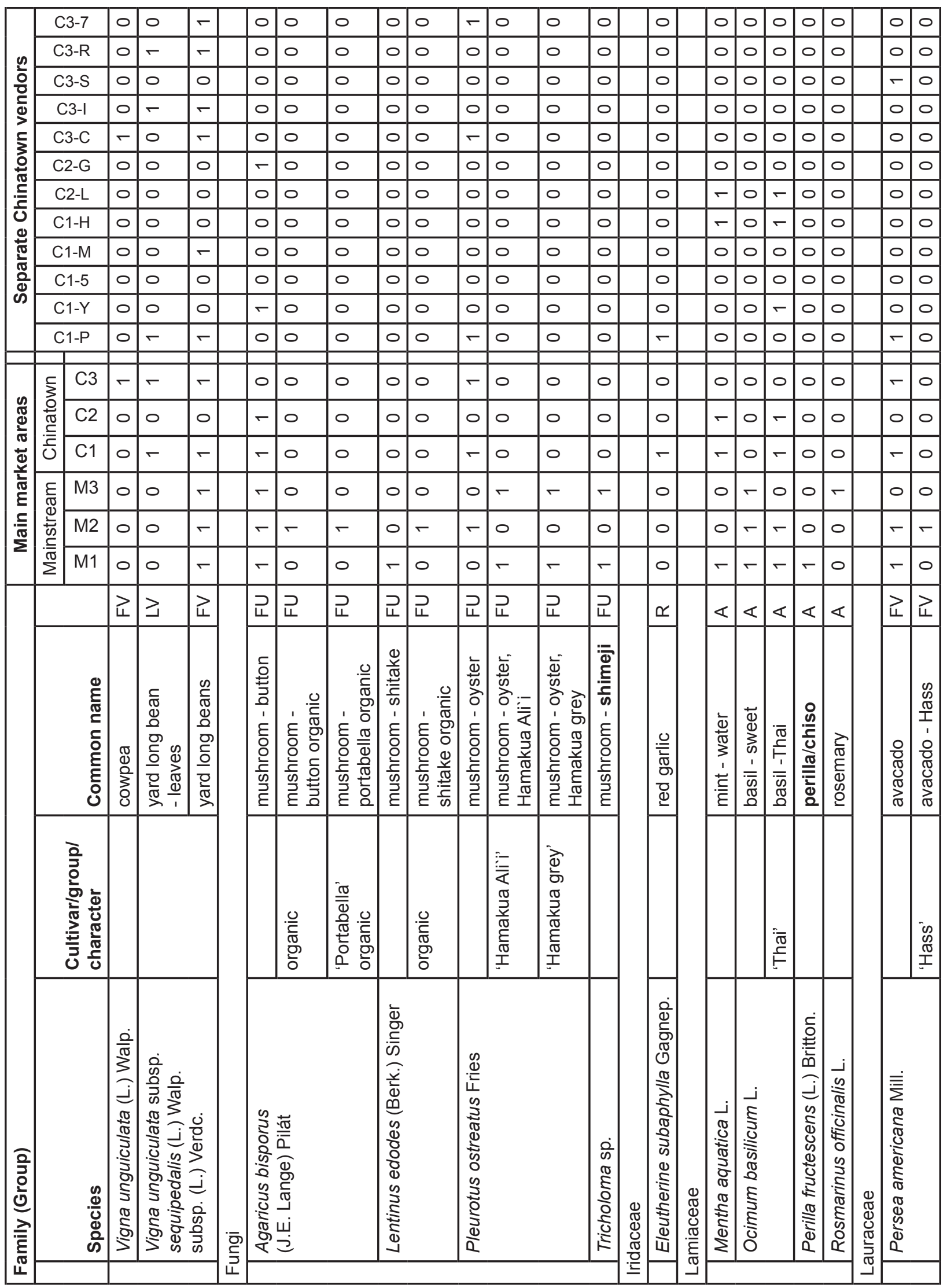


Nguyen et al. - Vegetation Analysis of Urban Ethnic Markets Shows

Supermarket Generalists and Chinatown Ethnic-specialist Vendors

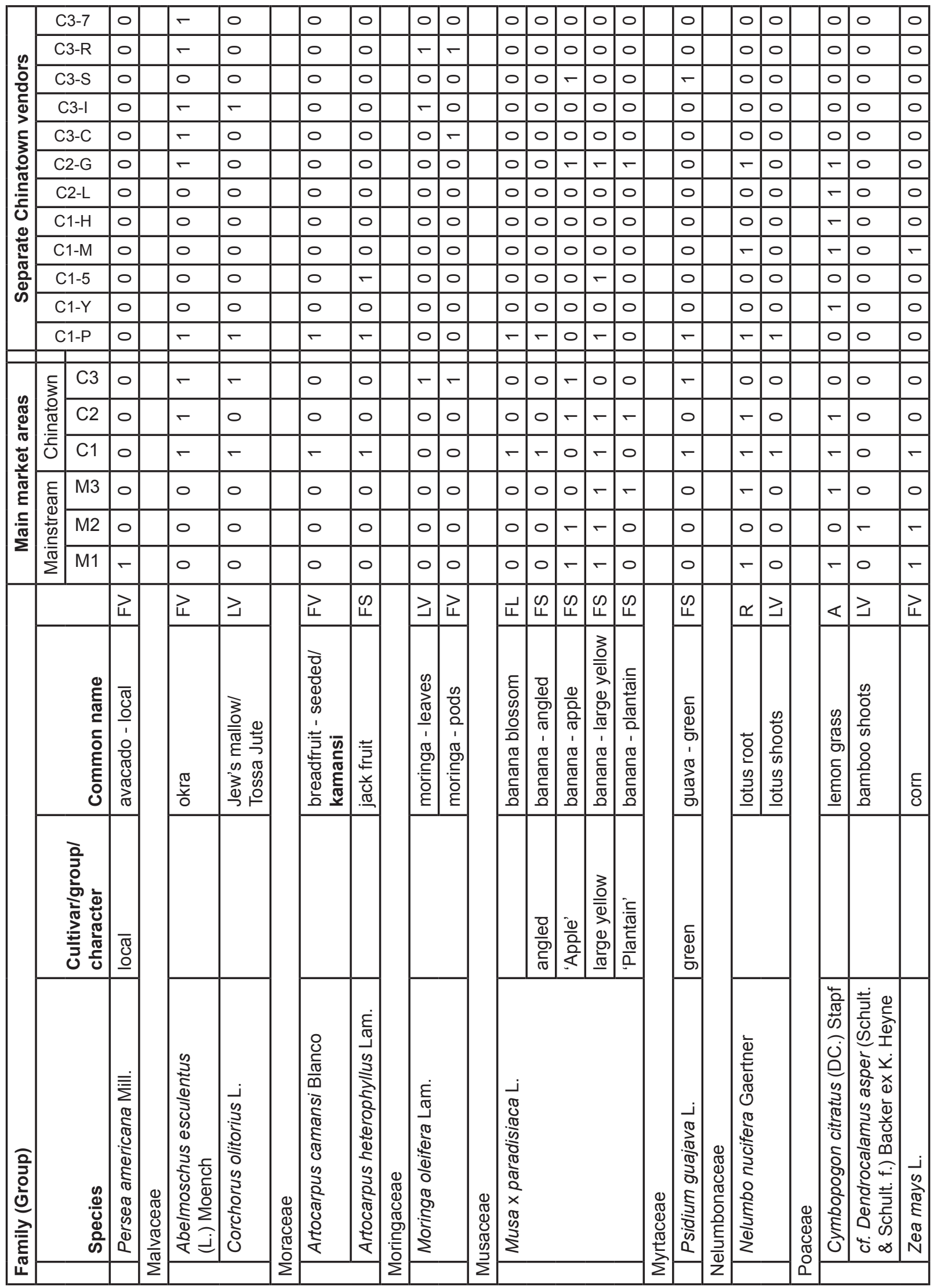

www.ethnobotanyjournal.org/vol6/i1547-3465-06-063.pdf 


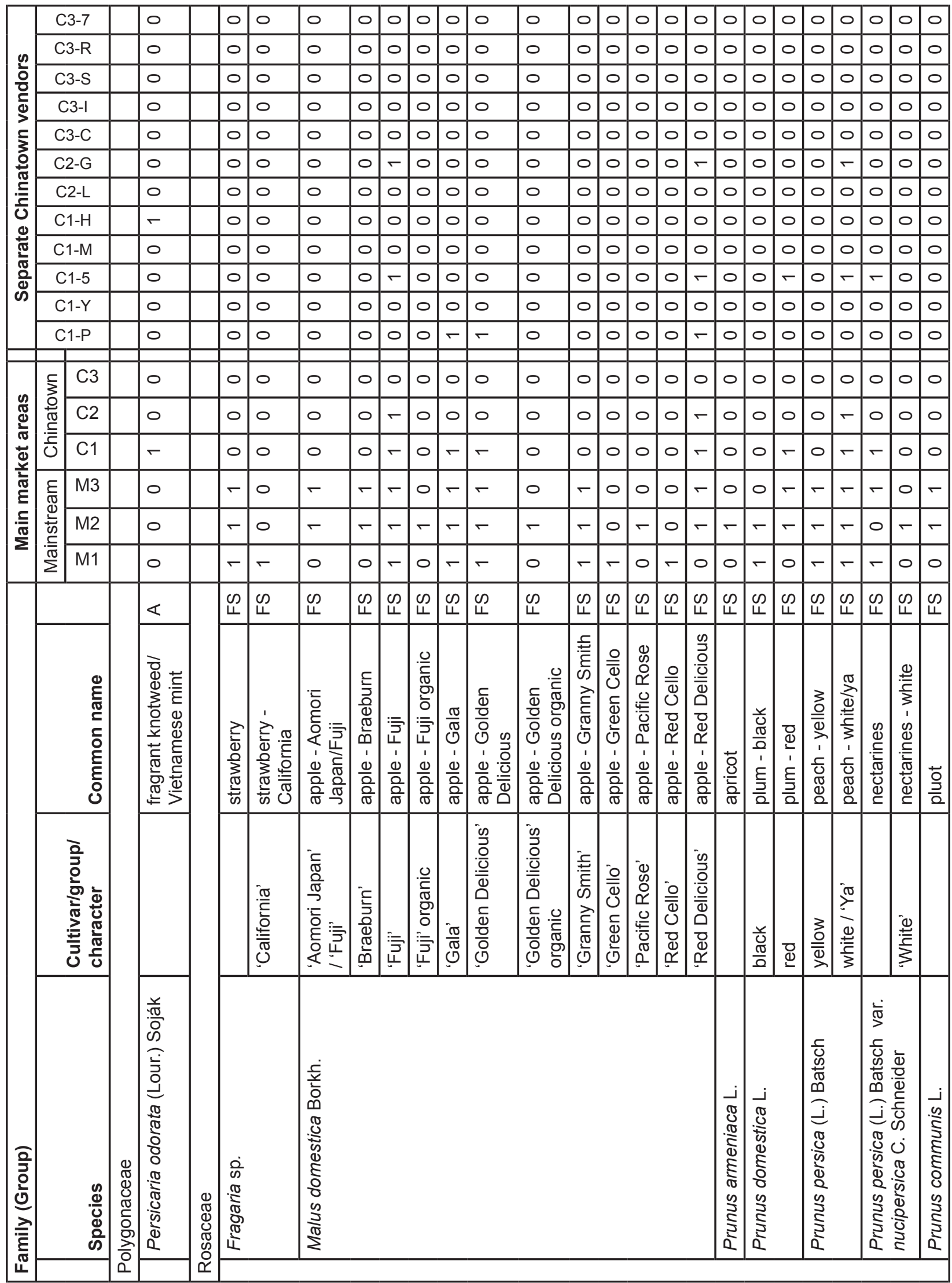


Supermarket Generalists and Chinatown Ethnic-specialist Vendors

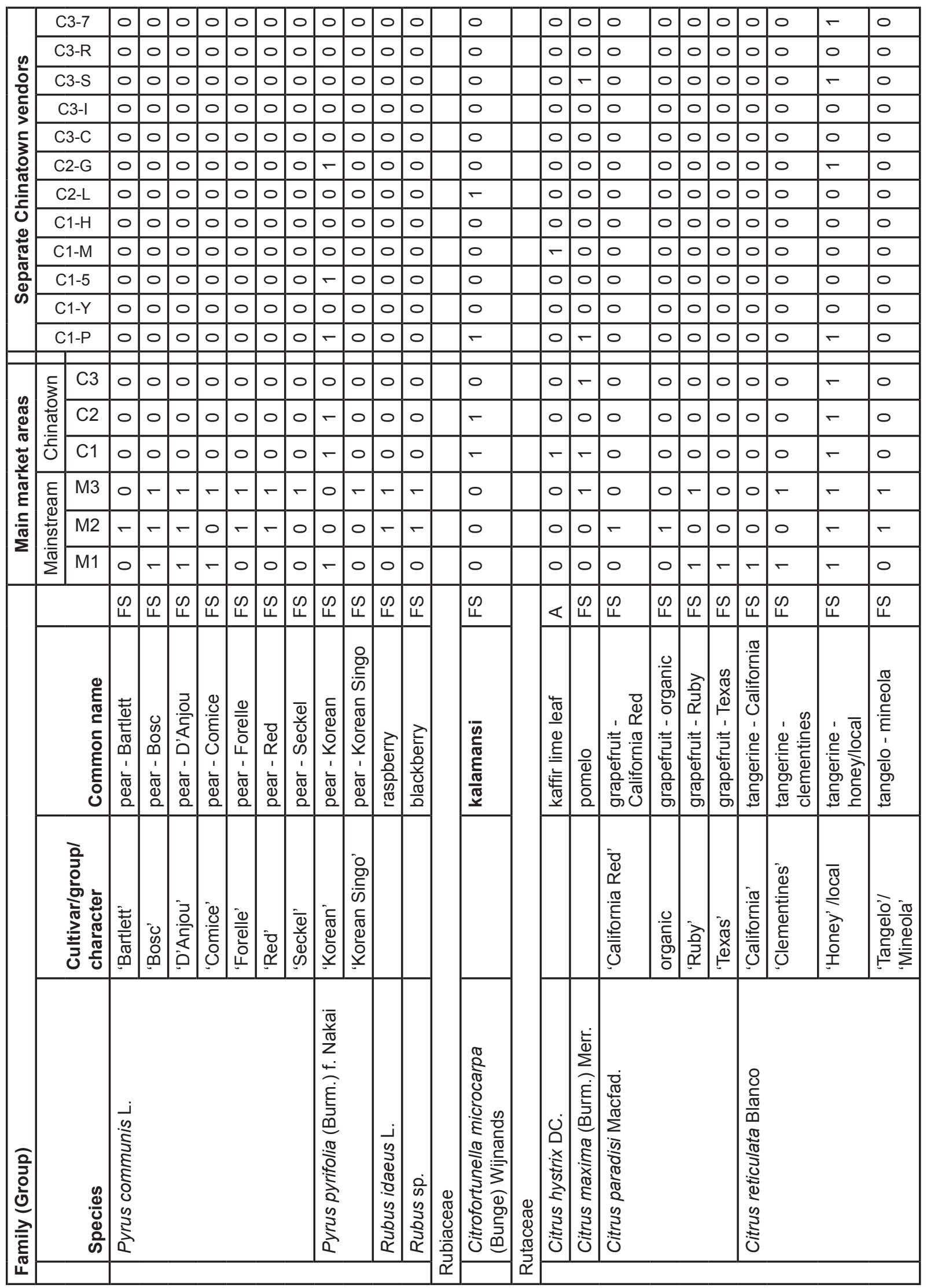




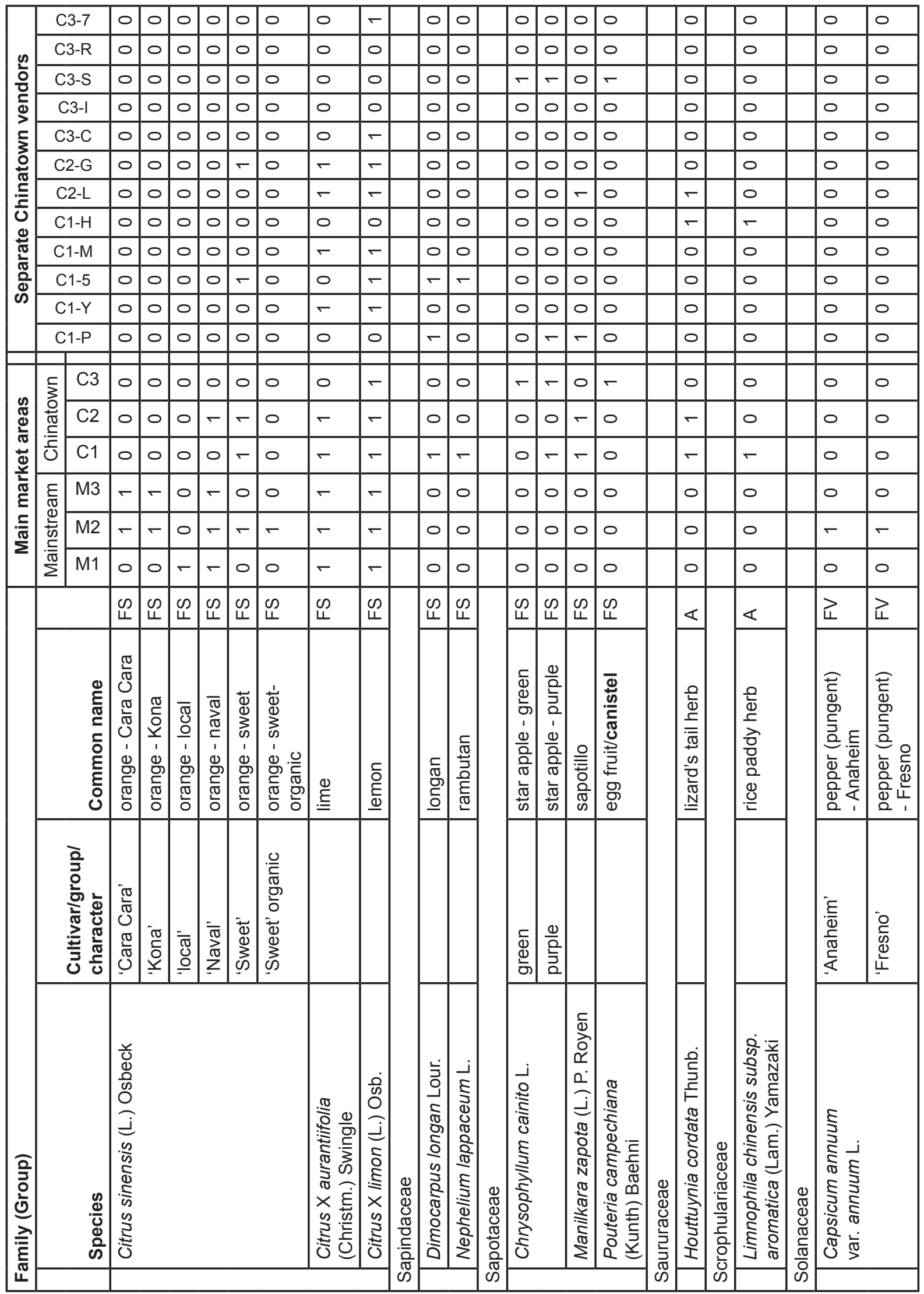


Nguyen et al. - Vegetation Analysis of Urban Ethnic Markets Shows

Supermarket Generalists and Chinatown Ethnic-specialist Vendors

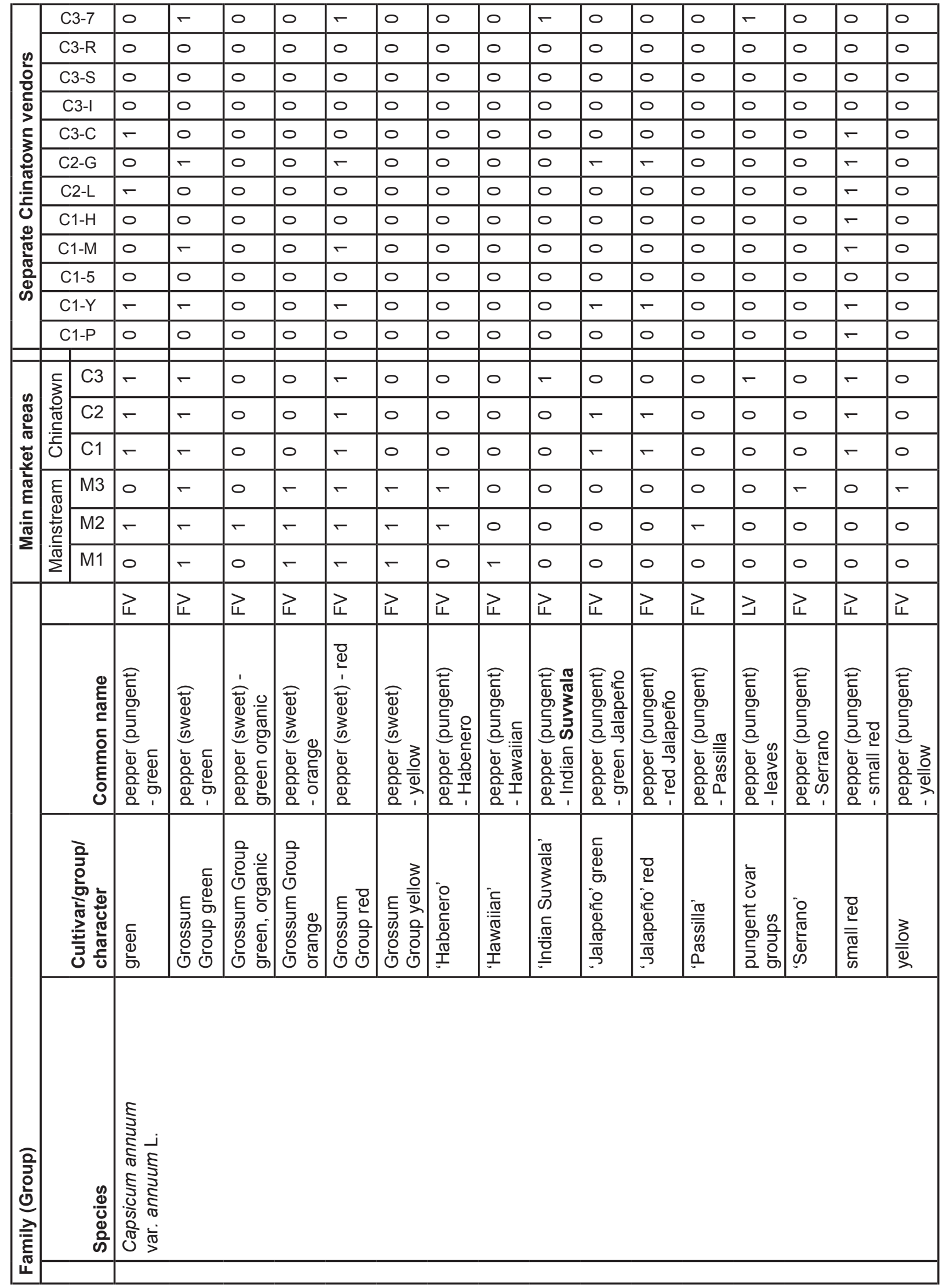




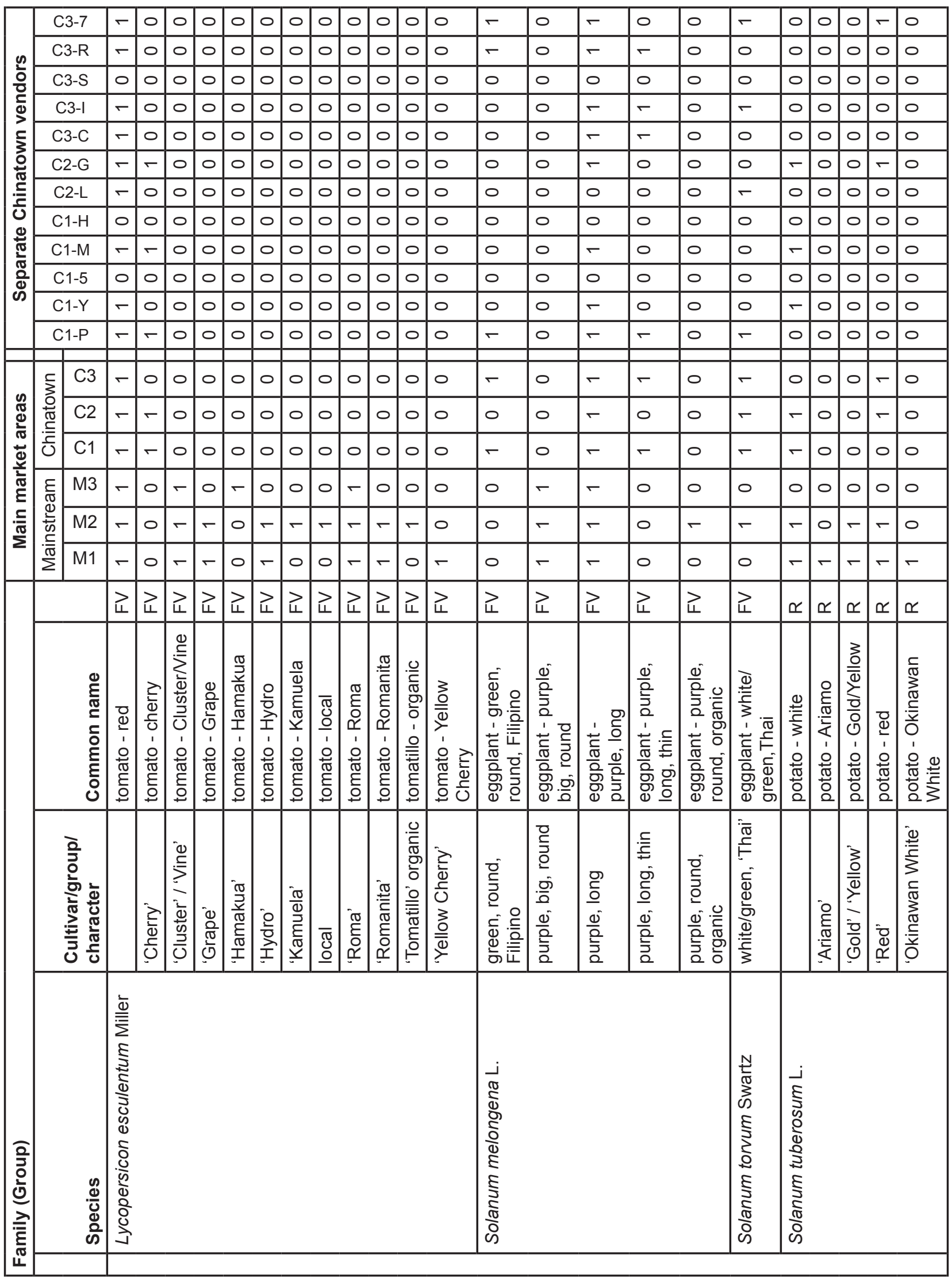




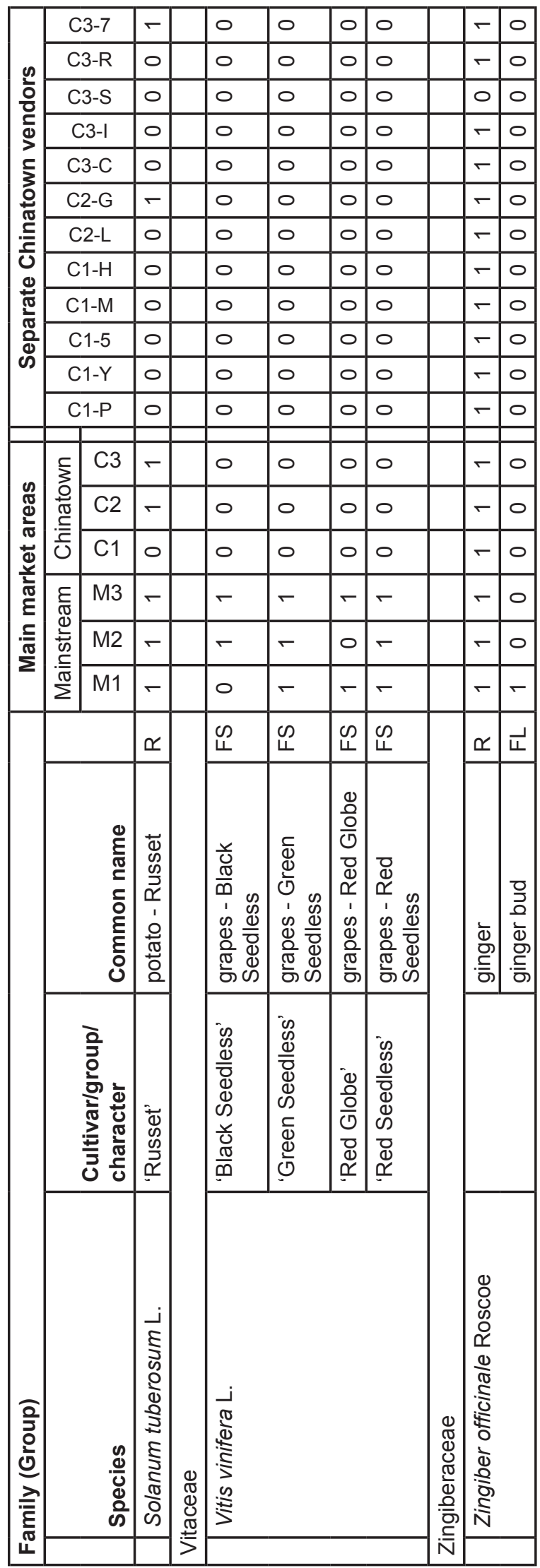


